\title{
REVIEW ON CLIMATE CHANGE IMPACTS AND ITS ADAPTATION STRATEGIES ON FOOD SECURITY IN SUB-SAHARAN AFRICA
}

\author{
Merertu Berhanu ${ }^{1}$ and Alemayehu Oljira ${ }^{2}$ \\ ${ }^{1}$ Department of Agricultural Economics and Agribusiness Management Jimma University College of \\ Agriculture and Veterinary Medicine \\ ${ }^{2}$ Department of Agricultural Economics and Agribusiness Management Jimma University College of \\ Agriculture and Veterinary Medicine
}

*corresponding author: merertuberhan@gmail.com

\begin{abstract}
Agriculture and food security are key sectors for intervention under climate change and highly sensitive to climate change. In Sub-Saharan Africa, agriculture-the mainstay of rural livelihoods-is particularly vulnerable to the adverse impacts of climate change, and the adaptive capacity of rural smallholders is extremely low. Agricultural Production is highly vulnerable even to low-end predictions for global mean temperatures in 2100, with major implications for rural poverty and for both rural and urban food security. In recent years it has become clear that climate change is an inevitable process. In Sub-Saharan Africa, the expectation is that climate change will have an especially negative impact on agriculture and food security, not only a result of projected warming and rainfall deficits, but also because of the vulnerability of the population. The impact upon agriculture and food security will be of great significance Sub-Saharan Africa. To further investigate the link between climate change, agriculture and food security the realist review method was employed. Analysis of the literature found consistent predictions of decreased crop productivity, land degradation, high market prices, and negative impacts on livelihoods, and increased malnutrition. Adaptation strategies were heavily discussed as a means of mitigating a situation of severe food insecurity across the entire region. This is linked to issues of development, whereby adaptation is essential to counteract the negative impacts and improve the potential of the population to undergo development processes. Findings additionally revealed a gap in the literature about how nutrition will be affected, which is of importance given the links between poor nutrition and lack of productivity.
\end{abstract}

Keywords: climate change; food security; adaptation; development; Sub-Saharan Africa

http://dx.doi.org/10.21776/ub.agrise.2019.019.3.3

Received 03 January 2019

Accepted 27 July 2019

Available online 25 August 2019

\section{INTRODUCTION}

Agriculture and food security are key sectors for intervention under climate change and highly sensitive to climate change. Even a 2C (low prediction) rise in global mean temperatures by 2100 , in the range of the IPCC low emissions (B1) scenario, will destabilize current farming systems (Easterling et al., 2007). Climate change has the potential to transform food production, especially, the patterns and productivity of crop, livestock and fishery systems, and to reconfigure food distribution, markets and access (Nelson et al., 2009). Climate change will bring further difficulties to millions of people for whom achieving food security is already problematic, and is perhaps humanity's most pressing challenge as 
we seek to nourish nine billion people by 2050 (Godfray et al., 2010).

Climate change will affect all four dimensions of food security: food availability, food accessibility, food utilization and food systems stability. It will have an impact on human health, livelihood assets, food production and distribution channels, as well as changing purchasing power and market flows. Its impacts will be both short term, resulting from more frequent and more intense extreme weather events, and long term, caused by changing temperatures and precipitation patterns, people who are already vulnerable and food insecure are likely to be the first affected. Agriculture based livelihood systems that are already vulnerable to food insecurity face immediate risk of increased crop failure, new patterns of pests and diseases, lack of appropriate seeds and planting material, and loss of livestock (IPCC, 2007; FAO, 2008).

Approximately 80 percent of poor people in Sub-Saharan Africa continue to depend on the agricultural sector for their livelihoods, but-unlike in other regions of the world-agriculture in SubSaharan Africa is characterized by very low yields due to agro-ecological features, poor access to services, lack of knowledge and inputs, and low levels of investment in infrastructure and irrigation. In addition, high population growth rates, especially in rural areas, intensify pressure on agricultural production and natural resources and further complicate the challenge of reducing poverty. Against this background, potential climate change poses a significant additional challenge to the future of agriculture in the region. Climate change could cause serious deterioration of rural livelihoods and increase food insecurity in SubSaharan Africa (Thompson et al., 2010; FAO, 2008).

Nevertheless, rainfed farming continues to dominate agricultural production in Sub-Saharan Africa, covering around 97 percent of total cropland, which exposes agricultural production to high seasonal rainfall variability. Although irrigation systems have been promoted in the region, irrigation infrastructure has not expanded as expected mainly due to lack of demand for irrigated products, lack of access to affordable complementary inputs, poor market access, unfavorable topography, low-quality soils, and low incentives for agricultural intensification (Gbetibouo. and Ringler, 2009; IFPRI, 2011).

Africa is commonly identified as a region highly vulnerable to climate change, particularly south of the Sahara. This is based on the social, economic, and political constraints that determine the capacity of human systems to cope with external stressors such as climate change, and the existing burden of climate-related hazards, including high prevalence of food insecurity (Brown et al. 2009; cooper et al., 2008). Africa is also sensitive to climatic hazards, being dependent upon local natural resources for livelihood activities such as agriculture, pastoralism, and fishing (wlokas, 2008; Osbahr et al., 2008).

Environmental stressors thus place a large proportion of the population at risk of adverse outcomes (Gregory et al., 2005; cooper et al., 2008). Projections indicate that warming in Africa will be greater than the global annual mean, with an average increase of $3-4{ }^{\circ} \mathrm{C}$ over the next century (Boko et al., 2007). Warming is projected throughout the continent and in all regions, although there is variability in the magnitude and speed of change. The southern region and its western margins are expected to see rainfall decrease, especially during the winter harvest months. East Africa is likely to see an increase in annual mean rainfall, whereas projections are uncertain for the Sahel, Guinean Coast, and southern Sahara. Across Sub-Saharan Africa, it is expected that when rain does fall, it will occur increasingly in high intensity, sporadic rain events (Christensen et al., 2007).

The impact of climate change on food security has been identified as a major area of concern given marginal climatic conditions in many parts of Africa, subsistence livelihoods, and limited resources for adaptation (FAO, 2010). In particular, the predominance of rain-fed agriculture in much of Sub-Saharan African results in food systems that are highly sensitive to rainfall variability (cooper $e t$ al.2008; Jones and Thornton, 2009).

Food security may be defined as a situation whereby all people, at all times, have physical, social and economic access to sufficient, safe and nutritious food to meet their dietary needs and food preferences for an active and healthy life (FAO, 2008; WSF, 2009). Three components of food security are evident in this commonly used 
definition: availability, access, and utilization, all of which are climate sensitive. Availability relates to the production of food, in terms of its physical presence in a region. Crop productivity and food stocks, for example, relate to food availability. Access is characterized by the ability of an individual or household to obtain food. This depends on food prices, market accessibility, employment, and distribution of wealth (Verdin et al., 2005). Utilization is the ability of humans to derive full biological benefits from food, based on nutritional value, socio-cultural value, and food safety (Gregory et al., 2005; Ford, 2009).

Food insecurity occurs when food systems are stressed such that food is not available, accessible, or utilization is constrained. Across Sub-Saharan Africa, communities have extensive experience in dealing with climatic uncertainties and food security implications (Roncoli et al., 2001; Stock, 2004). Subsistence livelihoods have evolved a number of coping mechanisms to manage weather variability, including drought years and low crop yield. Commonalities in coping are evident across diverse regions, involving a complex hierarchical decision-making process of sacrifice and use of support networks to endure periods of food insecurity (Roncoli et al., 2001; Stock, 2004).

These strategies initially involve responses including alterations to diet to include more famine foods, and during times of acute and or prolonged stress borrowing from kin, selling productive assets, and eventually migration. As famine progresses, survival strategies thus become more desperate, whereby domestic resources are increasingly committed and potential for reversing the strategies become more constrained. Historically, recovery has often been feasible (Stock, 2004), especially where detrimental climatic events have been spread out in space and time. The challenge that climate change presents is that drought and intense rain events will become more frequent, and are even projected to become the normal climatic state (Christensen et al., 2007).

Given poor progress on mitigation and inevitable warming due to historic emissions, we are locked in to some climate change impacts (Christensen et al., 2007; Ramanathan, 2008). Adaptation will be unavoidable, raising the importance of identifying and examining opportunities for developing anticipatory responses, particularly for vulnerable populations (Osbahr et al., 2008; Badjeck et al., 2010).

The importance of ecological and climatic processes for food production, and sensitivity of African food systems to climate, makes climate change a concern for food security. Indeed, the ability to achieve food security has broader implications for development and health, and is thus vitally important for future considerations of international development in the region. While the FAO has examined this link on a global level (FAO, 2010), and there is an emerging body of case study research on climate change and food security in Africa, limited research has examined the current state of knowledge at a regional level. This paper systematically reviews the peer-reviewed literature on the impact of climate change on agriculture and food security in Sub-Saharan Africa, to characterize and synthesize our current understanding on the problem, and identify priorities for future research.

The specific objectives of the review are to:

a. review the impact of climate change upon food security in terms of availability, access, and utilization and,

b. review the potential climate change adaptation strategies upon food insecurity in terms of availability, access, and utilization

\section{REVIEW METHODOLOGY}

A systematic review method was used to review literature related to climate change impacts on agriculture and food security in Sub-Saharan Africa. A realist review method was used. The realist approach builds upon the principles of the Cochrane systematic review, however seeks explanation, rather than empirical truth (Pawson et $a l ., 2005)$. The realist review often includes tighter inclusion criteria and a smaller number of documents than other review approaches, with a focus on depth rather than breadth and the use of predominantly qualitative critical analyses. This method provides an appropriate tool to understand food security as it is embedded with in the complex social, cultural, and ecological systems, which will affect vulnerability and adaptive capacity. To include only up-to-date information, a maximum time frame of 10 years is usually placed on the age of the works to be included in the review. Manual searching and Google scholar search strategies were performed in this literature review from 
different databases. Finally, the full text documents were assessed to evaluate the relevance of the paper particularly for this review. Papers both published and unpublished in English language were included in this review.

\section{DISCUSSION}

This part presents the systematic review of climate change impacts on food security in Sub-Saharan Africa. The first section presents the impacts of climate change on food security in Sub-Saharan Africa in terms of three components of food security (availability, access, and utilization). Availability was the primary focus of food security research, typically in relation to expectations of decreased crop productivity and land degradation. Access highlighted impacts on food prices and the ability to procure food, as well as impacts on livelihoods. Utilization received limited attention in the literature, and was only noted indirectly with respect to malnutrition; this is consistent with climate change and food security research in other regions. The second section presents the reviews adaptive strategies presented in the literature included food source alternatives, land degradation reduction, technology inputs, livelihood transitions, natural resource management, and policy and community development programmes. The articles varied in their spatial approach. All were Africaspecific studies, mostly with a Sub-Saharan Africa focus, but some used country or community case studies to explore how the issues applied in practice. Studies did not explicitly state their bias towards rural subsistence systems, but agrarian societies were largely the focus of research. This is perhaps due to the greater interaction of these communities with the natural environment, thus making the impact of climate change more direct.

\section{REVIEW ON THE IMPACTS OF CLIMATE CHANGE ON FOOD SECURITY}

\section{Impacts of climate change on food availability}

Food availability refers to the existence of sufficient quantities of food with appropriate quality, and supplied through domestic production or import. Food availability is probably most frequently used as a measure of food security and it has a channel with climate change which directly affects food security (Thompson et al., 2010). The major direct impact of climate change is expected to have on food security is through food availability component due to changes in agricultural productivity (Wlokas, 2008). Food availability in Sub Saharan Africa is directly affected by many aspects of climate change like temperature increase, change in rainfall amount and patterns, rising atmospheric concentrations of $\mathrm{CO} 2$, change in climatic variability and extreme events and sea water rise (Oyiga et al., 2008; Zewdie, 2014).

Literature indicate the most direct impact that climate change is expected to have on food security is through availability due to changes in crop productivity. Sub-Saharan Africa is characterized by the reliance of a heavy segment of the population upon local resources for food. Many communities rely largely or solely upon their own subsistence farming for their food needs (Wlpkas, 2008), with marginal groups especially dependent upon climate-sensitive resources (Ziervogel et al., 2006). With the exception of mid- to high-latitude regions of Africa, where crop productivity may actually increase as a result of climate change (Jones and Thornton, 2009), it is projected that mean crop productivity will decrease across SubSaharan Africa (Christensen et al., 2007).

Higher temperatures, for example, are expected to have an overall negative impact on crop productivity through decreased crop growth and duration (Gregory et al., 2005). The implications of climate change for food availability in Sub-Saharan Africa are generally expected to be severe. This is primarily due to the vulnerability of subsistence farmers, who are believed to have a low capacity to cope with environmental stressors (Gregory et al., 2005). Projected decreases in crop yields, relate to climatic impacts on both soil and water. Warming and abnormal rainfall deficits are expected to produce drought, with more frequent high intensity rain events additionally contributing to soil degradation and desertification (Azim-Ali, 2007; Edwards, 2007; Lal, 2009).

Soil erosion creates problems regarding viability of land for agriculture, as nutrient depletion limits the ability of many crops to prosper (Lal, 2009). A lack of good quality soil not only reduces its yield potential, but also limits the future potential of the land, as increasingly greater quantities and types of inputs are required to make the soil productive .Soil degradation is furthermore 
a problem based on the limitations created in terms of what types of crops may be grown. Some crops may be seen as more resilient in poor conditions, but the result is less diversification of crops, and thus a narrower field of food sources, with resulting health implications (Azim-Ali, 2007.

Soil degradation has implications for the water absorptive capacity of soil and water availability for agricultural production. At increasing levels of soil degradation, soil capacity to absorb water declines, increasing runoff and further exacerbating soil degradation. Not only does this result in the inability to utilize the most significant input to agriculture, but subsequent water run-off additionally takes top soil with it, further draining the soil of essential nutrients (Edwards, 2007). Water presents further issues in terms of how it is utilized. Rain-fed farming systems are the dominant form of agriculture among subsistence farmers in Africa (Cooper et al., 2008). This technique is considered more affordable than irrigation because of the low technology requirement, but it also increases vulnerability based on heavy reliance upon rainfall for water resources. Subsistence agricultural systems are thus particularly sensitive to increased volatility of rainfall and the resulting impacts on food crop yields (Cooper et al., 2008; Verdin et al., 2005).

The UN Millennium Project has recognized water as a key issue in relation to food security and identified increased irrigation of crops as a viable adaptive response. While increased stress on water resources is undoubtedly a significant concern, it has been argued by some that irrigation will further exacerbate poverty due to the costs to farmers already under stress (Lal, 2009; Ziervogal et al., 2009). Furthermore, as water becomes scarcer, increased competition for water resources may constrain access by vulnerable subsistence populations and smallholder farmers; potential diversion of water for industrial and domestic use will limit agricultural access (Odeny, 2009). Climate change is thus projected to restrict the availability of irrigation, with the cost of building and maintaining the technology in many cases greater than potential benefits (Azim-Ali, 207). Water insecurity is closely linked to food insecurity, and thus the stresses upon water resources that will be created by climate change will have significant impacts upon crop productivity.

\section{Impacts of climate change on food access}

Access to food refers to the ability of individuals, communities and countries to purchase food in sufficient quantities and quality (Ludi, 2009). In Sub Saharan countries, households fail to access food for many reasons like high food price, access to markets, the level of poverty, employment condition, educational status and property rights (Oyiga et al., 2008; Zewudie, 2014).

Access is based on the ability to procure food This may be impeded on both sides of the consumption process, with high food prices or lack of financial capital to acquire goods. While a large proportion of the African population relies primarily upon subsistence agriculture, markets have long been important as a secondary source of food. In general, there has often been a-hungry season\| from June to August, when crop yields do not meet demands, and food must largely be bought from markets (Brown et al., 2009). There is concern in the literature that this -hungry season\| will become longer amidst increasingly poor crop productivity (Brown et al., 2009).

Consumption of purchased food also increases during drought years (Gregory et al., 2009), and as drought and low crop productivity become increasingly common as a result of climate change, reliance upon these purchased foods is expected to increase. At the same time, rising food prices and unemployment may exacerbate the ability of people to access them. Food prices are expected to increase as population growth puts increased pressure on supplies, and imports become more expensive (Brown et al., 2009; Gregory et al., 2009). The latter will largely be connected to developed countries retaining surpluses for their own population, or transitioning from the use of crops for food to using them for biofuels (Brown $e t$ al., 2009; Lal, 2009).

Those who derive their livelihood from natural resources will additionally suffer increased food insecurity, based on smaller crop yields limiting availability of food for both personal consumption and as a source of capital (Wlokas, 2008; Osbahir et al., 2008). Lack of capital is identified as a major constraint in the ability of poor farmers to adapt, thus making them much more sensitive to climate change Bryan et al., 2009). With rain-fed agriculture and pastoralism being the primary livelihood options in Sub-Saharan Africa, there are a great many people who are vulnerable, and who 
could see their financial capital seriously limited (Cooper et al., 2008).Limited financial means, combined with expectations of high food prices, will thus seriously affect accessibility, and serve as an additional source for potential food insecurity in the face of climate change.

\section{Impacts of climate change on food utilization}

Perhaps the most significant component of food security in a changing climate, but least studied, is utilization. Even when availability and accessibility are not infringed upon, if food sources are not able to contribute to a balanced, nutritious diet, then the implications for health and productivity of the population could be significant (WSF, 2009). Health is of vital importance to the ability to engage in livelihood activities and make a valuable contribution to society, as well as for personal quality of life (Stock, 2004). The cultural aspects of food production and consumption are also widely acknowledged (Menasche et al., 2008; Wahlgvist and Lee, 2007).

Our review identified limited research related to climate change impacts on utilization in relation to food security. Nutritional disorders, while extensively researched and represented in the peerreviewed literature, were rarely characterized in relation to climate change. Malnutrition is highlighted as an associated problem with food insecurity generally (Wlokas, 2008; Azim-Ali, 2007), and issues such as micronutrient deficiency and protein deficiency are mentioned specifically (Odeny, 2007), as well as discussion of the potential nutritional benefits that certain food sources offer (Azim-Ali, 2007; odney, 2007).

Further investigation into how climate change may affect incidence or prevalence of specific disorders, and the impact they would have upon the population as a whole, however, are generally absent. Cultural implications have also not been assessed. When diet modification occurs, the culture-determined values, attitudes, and beliefs that affect food selection and food habits will need to be taken into consideration (Menasche et al., 2008; Wahlgvist and Lee, 2007). Where production and consumption of certain foods is linked to culture, changes can additionally have psychological implications, and therefore must be a considered (Mead, 2008).

\section{Impact of Climate Change Adaptation Strategies on Food Security}

Along with discussion of the mechanisms by which climate change impacts food security, adaptation strategies have been proposed in the literature.

\section{Impact of climate change adaptation strategies on food availability}

In relation to food availability, extensification and intensification $^{1}$ are the major options documented to improve crop yields. One estimate suggests that extensification could increase cereal production in Africa 47 percent by 2020. It also has implications however, for generating further environmental degradation, with land coverage changes and deforestation found to contribute to $\mathrm{CO} 2$ emissions (Gregory et al., 2008). Generally, intensification of agricultural land is seen as the most viable solution. This would require improving the quality of soil and maximizing usage of water resources, which often require greater inputs.

Edwards (2007) argues for the benefits of organic agriculture, whereby compost is used as a natural fertilizer. Projects in Ethiopia have shown much higher yields, both in comparison with no inputs and with chemical fertilizers (Edwards, 2007). Manure ${ }^{2}$ is also seen as an input that could improve soil quality, and thus permit intensification (Verdin et al., 2005). There remains debate, however, as to the potential for organic fertilizers to meet demands in soil fertility, and a more traditional approach has been the promotion of chemical fertilizers. While very common and quite heavily used in the developed world, these are relatively absent in Sub-Saharan Africa (Gregory et al., 2008; Brown et al., 2009; Lal, 2009).

While valuable for improved agricultural yields, increased use of fertilizer may also contribute to climate forcing through the introduction of increased nitrous oxide emissions from soils. With water shortages expected to occur alongside climate change, maximization of water resources is an additional concern, especially for intensification to become successful. Crop irrigation has seen some success, and it is argued by some that it should be more widely implemented (Gregory et al., 2008; Lal, 2009). Others however,

\footnotetext{
1 Intensification (of agriculture) aiming to achieve maximum production within a limited area. Often contrasted with extensive

${ }^{2}$ Manure is animal dung used for fertilizing land
} 
highlight the limitations of subsistence farmers, and suggest that small-scale and affordable solutions would be more beneficial (Brown et al., 2009; Cooper et al., 2008).

To better take advantage of limited water resources, certain crop varieties are also identified as important components of adaptation strategies. Genetic modification is one possibility, in terms of the creation of drought-resistant or high-heat tolerance crop varieties (Gregory et al., 2008; Brown et al., 2009; Odeny, 2007). High-yielding seeds are additionally seen as a possibility to increase crop productivity (Brown et al., 2009). Furthermore, certain crop varieties have been identified and classified as underutilized, based on their potential value as being both highly productive in poor soil conditions and nutritionally beneficial (Azam-Ali, 2007; Odeny, 2007).

Further research is recommended to identify additional underutilized crops. A final adaptive strategy for improving crop yield is modifying agricultural practices more directly. Crop diversification is one possibility, whereby dual-land use agricultural systems may be used to grow some of the more staple crops for a specific region, along with an -insurance crop in case of crop failure (Osbahr et al., 2008). This would reduce food insecurity, whereby there is always at least one crop to fall back on (Ziervogel et al., 2006). No-tillage farming is additionally seen as less disruptive to the soil, helping to maintain soil nutrients and water availability (Lal, 2009).

\section{Adaptation Strategies to Accessibility}

In terms of accessibility, the primary adaptive strategy to minimize vulnerability of financial capital, and thus improve market access when subsistence crops are not plentiful enough to provide food security, is livelihood diversification (Cooper et al., 2008; Osbahr et al., 2008). This is believed to allow for sources of income that are not fully reliant upon the natural environment, and thus less vulnerable to climate change. Off-farm employment is considered particularly viable for youth, who could earn money to send back to their families (Osbahr et al., 2008). Physical market accessibility remains a challenge with respect to general improvements in urban, rural, and transportation infrastructure (Gregory et al., 2008; Bryan et al., 2009).

\section{Adaptation Strategies Related to Food Utilization}

Adaptive strategies related to the utilization component of food security are mostly implicit in discussion of certain underutilized crops, and their nutritional value. Bambara groundnut for instance is seen as a rich source of protein and energy (Azam-Ali, 2007). Pigenopea ${ }^{3}$ is also identified as high protein, a rich source of carbohydrates, and an important source of various vitamins and minerals (Odeny, 2007). Nonetheless, adaptation of these crops is suggested more to improve availability, and utilization adaptation was not a major consideration in the literature.

Access to information about climatic changes and potential adaptive strategies, in order to effectively promote practical adaptation, must also be provided to those subsistence farmers in SubSaharan Africa who will be most affected (Bryan et al., 2009). In many cases, existing recommendations for improved farming practices are already consistent with increased adaptive capacity to projected climate changes. Additional awareness among farmers that unfavorable climatic conditions are likely to become more common can further mitigate the danger that subsistence farmers will fall back on traditional coping strategies that may be maladaptive in light of climate change; with decreased opportunity to recover, adaptive capacity may be limited.

\section{CONCLUSION AND RECOMMENDATION \\ CONCLUSION}

Agriculture and food security are key sectors for intervention under climate change and highly sensitive to climate change. In Sub-Saharan Africa, agriculture-the mainstay of rural livelihoods-is particularly vulnerable to the adverse impacts of climate change, and the adaptive capacity of rural smallholders is extremely low. Agricultural production is highly vulnerable even to $2 \mathrm{C}$ predictions for global mean temperatures in 2100 , with major implications for rural poverty and for both rural and urban food security. In recent years it has become clear that climate change is an 
inevitable process. In Sub-Saharan Africa, the expectation is that climate change will have an especially negative impact on agriculture and food security, not only a result of projected warming and rainfall deficits, but also because of the vulnerability of the population. The impact upon agriculture and food security will be of great significance Sub-Saharan Africa. Analysis of the literature found consistent predictions of decreased crop productivity, land degradation, high market prices, and negative impacts on livelihoods, and increased malnutrition. In conclusion, the link between climate change and food security is clear and strong, though unequally explored. Availability impacts are by far the best researched, with ample evidence on how warming and rain deficits will impact crop productivity. Accessibility has also been significantly examined, especially in regards to concerns of rising food prices and the potential need for livelihood transitions. Academic research is limited, however, in linking climate change to nutritional disease prevalence and incidence. There is a large body of literature on what major disorders currently afflict many people in Sub-Saharan Africa, but little research has been done to examine whether any disorders will be disproportionately affected by climate change, or whether others may emerge as a more widespread problem. Research gaps thus exist in relation to the utilization mechanism of food security.

\section{RECOMMENDATION}

Sub-Saharan Africa is a region struggling with underdevelopment, and the high proportion of the population that is currently food insecure is undoubtedly linked. If Sub-Saharan Africa is ever to achieve a reality of development, it must break the cycle of poverty and malnutrition in which it is currently stuck.

The review shows climate change will have an especially negative impact on agriculture and food security, not only a result of projected warming and rainfall deficits. Therefore, the mechanism of increasing food security status of population by overcoming environmental problem is very important.

\section{REFERENCES}

Arimond, M.; Ruel, M.T. 2004. Dietary diversity is associated with child nutritional status:
Evidence from 11 demographic and health surveys. J. Nutr. 134, 1579-2585.

Assunção. J and Chein, F. 2009. Climate change, agricultural productivity, and poverty. Working Paper, Department of Economics, PUC-Rio de Janeiro, Brazil.

Azam-Ali, S. 2007. Agricultural diversification: The potential for underutilized crops in Africa's changing climates. Riv. Biol. 100, 27-37.

Badjeck, M.C.; Allison, E.H.; Hallsd, A.S.; Dulvy, N.K. 2010. Impacts of climate variability and change on fishery-based livelihoods. Mar. Policy. 34, 375-383.

Balisacan A., Piza, S.F., Safir, A. and Skoufias, E. 2011. Climatic variability and its impacts on household consumption in the Philippines. Unpublished manuscript. Washington, DC, World Bank.

Block, P. J., K. Strzepek, and B. Rajagopalan. 2007. Integrated Management of the Blue Nile Basin in Ethiopia: Hydropower and Irrigation Modeling, IFPRI Discussion Paper No. 700 (Washington, DC: International Food Policy Research Institute).

Blössner, M.; de Onis, M. 2005. Malnutrition: Quantifying the Health Impact at National and Local Levels; Environmental Burden of Disease Series No. 12; WHO Press: Geneva, Switzerland.

Boko, M.; Niang, I.; Nyong, A.; Vogel, C.; Githeko, A.; Medany, M. Osman-Elasha, B. Tabo, R.; Yanda, P. 2007. Africa. In Proceedings of the Working Group II Report -Impacts, Adaptation and Vulnerabilityll; Parry, M.L., Canziani, O.F., Palutikof, J.P., van der Linden, P.J., Hanson, C.E., Eds.; Cambridge University Press: Cambridge, UK.

Brown, M.E. 2009. Markets, climate change, and food security in West Africa. Environ. Sci. Technol. 43, 8016-8020.

Bruyn, G.W.; Poser, C.M. 2003. The History of Tropical Neurology: Nutritional Disorders; Science History Publications: Canton, MA, USA.

Bryan, E.; Deressa, T.T.; Gbetibouo, G.A.; Ringler, G. 2009. Adaptation to climate change in 
Ethiopia and South Africa: Options and constraints. Environ. Sci. Policy. 12, 413426.

Calzadilla, A., T. Zhu, K. Redhanz, R. S. J. Tol, and C. Ringler. 2009. Economywide Impacts of Climate Change in SubSaharan Africa, IFPRI Discussion Paper No. 873 (Washington, DC: International Food Policy Research Institute, 2009).

Christensen, J.; Hewitson, B.C.; Mearns, L.O. 2007. Regional Climate Projections. In Climate Change 2007: The Physical Science Basis: Contribution of Working Group I to the Fourth Assessment Report of the Intergovernmental Panel on Climate Change; Solomon, S., Qin, D., Manning, M., Eds.; Cambridge University Press: Cambridge, UK.

Cooper, P.J.M.; Dimes, J.; Rao, K.; Shapiro, B.; Twomlow, S. 2008. Coping better with current climatic variability in the rain-fed farming systems of Sub-Saharan Africa: An essential first step in adapting to future climate change? Agric. Ecosyst. Environ. 126, 24-35.

Declaration of the World Summit on Food Security. 2009. In Proceedings of World Summit on Food Security, Rome, Italy, 16-18 November.

DESA (United Nations, Department of Economic and Social Affairs, Population Division). World Population Prospects. 2009. The 2008 Revision; United Nations Publication: New York, NY, USA.

Easterling, W.E., P.K. Aggarwal, P. Batima, K.M. Brander, L. Erda, S.M. Howden, A. Kirilenko, J. Morton, J.[F. Soussana, J. Schmidhuber and F.N. Tubiello (2007). Food, fibre and forest products; in Parry, M.L., O.F. Canziani, J.P. Palutikof, P.J. van der Linden and C.E. Hanson, eds., Climate Change 2007: Impacts, Adaptation and Vulnerability. Contribution of Working Group II to the Fourth Assessment Report of the Intergovernmental Panel on Climate Change, Cambridge University Press, Cambridge, UK, 273 [313.

Edwards, S. 2007. Role of Organic Agriculture in Preventing and Reversing Land
Degradation. In Climate and Land Degradation; Springer: Berlin, Germany. pp. 523-536.

FAO (2007). The State of Food Insecurity in World, 2010. Rome, Italy.

FAO. 2006. Guidelines on Food Fortification with Micronutrients; WHO Press: Geneva, Switzerland.

FAO. 2008. Climate change and food security: a framework document. ROME

FAO. 2010. Impact of Climate Change, Pests and Diseases on Food Security and Poverty Reduction. In Proceedings of the FAO Committee on World Food Security (31st Session), Rome, Italy, 23-26. Sustainability

Fereday, J.; Muir-Cochrane, E. 2010. Demonstrating rigor using thematic analysis: A hybrid approach of inductive and deductive coding and theme development. Int. J. Qual. Methods 2006, 5, 1-11. Sustainability. 22732

Ford, J. 2009. Vulnerability of Inuit food systems to food insecurity as a consequence of climate change: A case study from Igloolik, Nunavut. Reg. Environ. Change. 9, 83-100.

Gbetibouo, G.A. and C. Ringler. 2009. Mapping South African farming sector vulnerability to climate change and variability: $A$ subnational assessment. IFPRI Discussion Paper No. 885 (Washington, DC: International Food Policy Research Institute).

Godfray, H.C.J., J.R. Beddington, I.R. Crute, L. Haddad, D. Lawrence, J.F. Muir, J. Pretty, S. Robinson, S.M. Thomas and C. Toulmin (2010). Food Security: The Challenge of Feeding 9 Billion People. Science, 327(5967): 812[818.

Gregory, P.J.; Ingram, J.S.I.; Brklacich, M. 2005. Climate change and food security. Philos. Trans. R. Soc. B, 360, 2139-2148.

IFPRI, 2011. How can African agriculture adapt to climate change? Insights from Ethiopia and South Africa in C. Ringler, E. Bryan, R.M. Hassan,Tekie Alemu, and M. Hillesland. 2033 K Street, NW. Washington, DC 20006-1002 USA. 
www.ifpri.org

IPCC (2007). Impacts, Adaptation and Vulnerability. Asia Climate Change 2007. Parry ML, Canziani OF, Palutikof JP, van der Linden PJ, Hanson CE (edn). Cambridge University Press, Cambridge, UK 469-506.

IPCC (Intergovernmental Panel on Climate Change). 2007. Climate Change: Impacts, adaptation and vulnerability. Contribution of Working Group II to the Fourth
Assessment Report of the IPCC. M. L. Parry, O.F. Canziani, J.P. Palutikof, P.J. van der Linden \& C.E. Hanson, eds. Cambridge, UK, Cambridge University Press.

IPCC. 2007. Climate Change $2007 \square$ Impacts, adaptation and vulnerability. Contribution of Working Group II to the Fourth Assessment Report of IPCC. Cambridge. UK. Cambridge University Press.Association between Cassava and the Paralytic Disease 